\title{
Seismic Response of Shear Distortion Type Buildings
}

\author{
P.A. Rekvava*
}

K. Zavriev Institute of Structural Mechanics and Earthquake Engineering, Tbilisi, Georgia

\begin{abstract}
A plastic hinge joints method is used to estimate the seismic nonlinear response of shear distortion type structures or large panel buildings. For consideration of interaction of building with the soil there is considered a complex model of soil-interface-building system containing soil in the form of isotropic half-space and building connected to each other in the zone of contact by non-elastically deformable hinge nodes. The large panel building is represented by a spatial system of plane stressed elastic structural members - wall panels and panel slabs coupled in discrete nodes by nonlinear zero length hinged connections. 3D nonlinear dynamic analysis of the soil-interface-building system is carried out by the substructures method using an implicit time integration scheme. There is given an example of a five story panel building with wide spacing 7.2-8.4 m. This study has taken into account the stochastic nature of the ground motion in Tbilisi region. The calculated values of response parameters at different levels of peak ground acceleration indicate that the reliability of the new generation panel building is satisfactory.
\end{abstract}

\section{INTRODUCTION}

The performance of shear distortion type structures or large panel buildings depends on the behavior of vertical wall panels and horizontal panel slabs connected to each other by vertical and horizontal key joints. The analysis of the earthquake consequences that occurred in many seismic regions of the world has shown that these buildings successfully perform the primary objective of earthquake engineering - protection of the health and safety of occupants. It should be noted that their specific damages from strong earthquake events are as follows: crack formation and opening, crushing of compressed concrete, yielding and rupture of some main reinforcement at connection regions and the presence of thin cracks in wall panels primarily on ground floors. Due to the sliding and rocking mechanisms the vertical and horizontal connections mainly shear and tensioncompression deformations are affected and nonlinear behavior is highly concentrated at key joint locations and at the contact surface between soil and building.

Large panel buildings with many stories and spacing normally are analyzed with simplified nonlinear models which neglect effect of spatial structural performance (Caccese and Harris EESD 1987) [1]. Some of the analytical models (Rekvava 9ECEE 1990) [2] (Astarlioglu et al. 12WCEE 2000) [3] are suitable for modeling 3D performance of large panel buildings under seismic loading. The nonlinear seismic analysis method based on the Finite Element Method (FEM) and substructures procedures for panel building considers more scalar parameters as measures of the damage sustained (Rekvava and Mdivani ITSAESE 2007) [4]. These parameters are also known as Engineering Demand Parameters (EDPs). The most common EDPs are the maximum story drift ratios, the maximum roof drift ratios or the maximum floor accelerations, that will be used with

*Address correspondence to this author at the K. Zavriev Institute of Structural Mechanics and Earthquake Engineering, Tbilisi, Georgia;

E-mail: rekvavapaata@yahoo.com fragility relations to determine performance of building system and components. This study focuses on the analytical model to assess the shear distortion type building seismic response using some phase of Performance-Based Earthquake Engineering (PBEE).

\section{OUTLINE OF NUMERICAL ANALYSIS}

The practical approach to PBEE considers a ground motion Intensity Measure (IM), structural response to calculate EDP, resulting damage analysis, which relates the EDP to Damage Measure (DM) and calculation of Decision Variable (DV), in terms that are useful to decision makers such as direct losses, downtime (or restoration time), and life safety risks (Moehle and Deierlein 13WCEE 2004) [5].

Direct assessment of seismic response EDP and DM of building begins with a careful assessment of the various modes of deterioration in the structural components that make up a building. In reinforced concrete panel building the primary structural components of the seismic force resisting system are the wall panels, horizontal panel slabs and key joints. Deterioration of key joints is associated with axial tension/compression, shear or a combination of these.

Based on the actual performance of panel buildings under strong earthquakes the idealized mechanical model, shown in Fig. (1), and plastic hinge joints method is developed by the author for simulating the inelastic response of the soilinterface-panel building system (Rekvava 14WCEE 2008) [6]. The panel building is represented by a spatial system of elastic substructures in plane stress - wall panels and panel slabs connected in points, corresponding to location of key joints, by the nonelastic hinge links (lumped plasticity model). The soil is simulated by the ensemble of $3 \mathrm{D}$ elastic finite elements in the form of elastic nonhomogeneous isotropic half-space.

The conditions of interconnection as separation and sliding (constructive nonlinearities) on the interface between the building and surrounding soil are modeled by contact elements, not passing the tension strength to surfaces belonging 


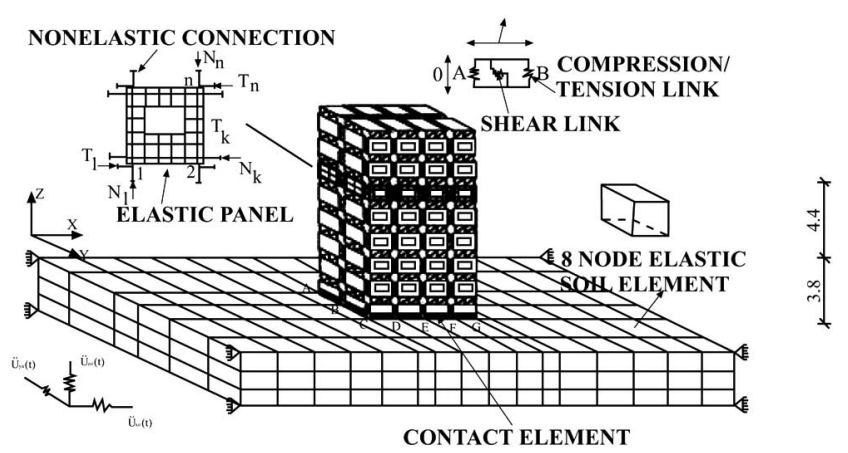

Fig. (1). Diagram of the soil-interface-panel building model.

to the building and soil. The contact element is assumed to have zero thickness and can be conceptually thought of as consisting of springs and Goodman joint element (Heuze and Barbour GED 1982) [7]. The Mohr-Coulomb yield criterion is used to simulate interface behavior.

The plots of shear (Fig. 2a) and axial (Fig. 2b) forces versus nodal displacements represent the deformability properties of reinforced concrete key joints for cracking (c), yielding (y) and ultimate (u) strength stages.

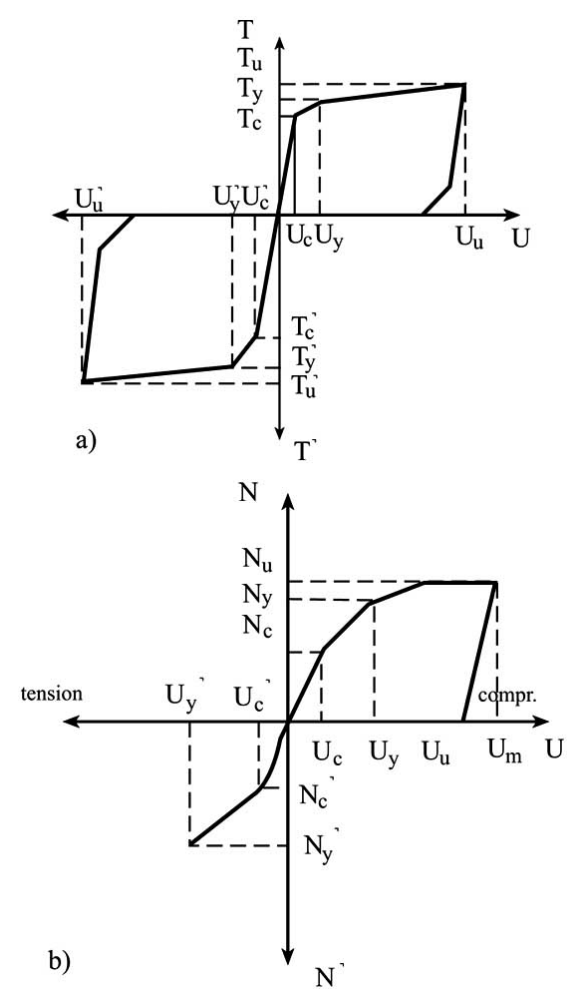

Fig. (2). Curves for cyclic response model.

The moment of entering into the phase of cracking, yielding and failure is specified by the von Mises plasticity formulation with the Mroz hardening theory (Rekvava 14WCEE 2008)[6].

The instantaneous backbone curves degrade as a function of the cyclic loading and thus can accurately simulate the response under different loading histories.
The model of the building for dynamic analysis is idealized as a multi degree of freedom (dof) system consisting of masses. The acceptable dynamic results can be obtained by associating mass with only a limited number of dof and assuming that no inertia forces act in the other dof. Thus, each mass is lumped at the level of the floor at nodes of structures interaction and at this stage may possess only three translation dof per node.

Equations of dynamic motion for assumed model of the soil-interface-panel building subjected to earthquake ground motion at the time $\mathrm{t}$ can be written as follows (Rekvava 14WCEE 2008)[6]

$$
\begin{aligned}
& \mathrm{MÜ}(\mathrm{t})+\mathrm{CU}(\mathrm{t})+\mathrm{F}(\mathrm{t})=\mathrm{P}(\mathrm{t}) \\
& \text { where } \quad \mathrm{P}(\mathrm{t})=-\mathrm{MB} \ddot{U}_{\mathrm{g}}(\mathrm{t})
\end{aligned}
$$

where $\mathrm{M}, \mathrm{C}$ are mass and damping matrices; $\mathrm{F}(\mathrm{t})$ is a vector of restoring (stiffness) forces; $U(t)$ is the nodal displacement vector; $\mathrm{B}$ is matrix of coefficient of quasi-static effects of seismic influence; $\ddot{U}_{g}(t)$ is a vector of the input ground acceleration time history, whose elements are given by the $x_{-}^{-}, y_{-}$ and z-components of ground acceleration.

The equations of motion (1) at time $\tau=t+\Delta t$ can be written as

$M \ddot{U}_{\tau}+\mathrm{CU}_{\tau}+\mathrm{F}_{\tau}=-\mathrm{MB} \ddot{U}_{\mathrm{g}}(\tau) \cdots$

Define the increments in acceleration, velocity, displacement and force occurring in the time increment $\Delta \mathrm{t}$ by

$\Delta \ddot{\mathrm{U}}_{t}=\ddot{\mathrm{U}}_{\tau}-\ddot{\mathrm{U}}_{\mathrm{t}} \quad \Delta \dot{\mathrm{U}}_{t}=\dot{\mathrm{U}}_{\tau}-\dot{\mathrm{U}}_{\mathrm{t}} \quad \Delta \mathrm{U}_{t}=\mathrm{U}_{\tau}-\mathrm{U}_{\mathrm{t}}$
$\Delta \mathrm{F}_{t}=\mathrm{F}_{\tau}-\mathrm{F}_{\mathrm{t}} \approx \frac{\partial \mathrm{F}_{\mathrm{t}}}{\partial \mathrm{U}_{\mathrm{t}}} \Delta \mathrm{U}_{t}=\mathrm{K}_{\mathrm{T}} \Delta \mathrm{U}_{t} \quad \cdots$

Substituting these expressions in Eq.(2), the incremental form of the equations of motion is obtained as follows:

$\mathrm{M} \Delta \ddot{\mathrm{U}}_{\mathrm{t}}+\mathrm{C} \Delta \dot{\mathrm{U}}_{\mathrm{t}}+\mathrm{K}_{\mathrm{T}} \Delta \mathrm{U}_{\mathrm{t}}=-\mathrm{MB} \ddot{\mathrm{U}}_{\mathrm{g}}(\tau)-\left[\mathrm{MU}_{\mathrm{t}}+\mathrm{C} \dot{\mathrm{U}}_{\mathrm{t}}+\mathrm{F}_{\mathrm{t}}\right] \cdots$

where $K_{T}$ is the tangent stiffness matrix of the model at time $\mathrm{t}$, which is a function of the nodal displacements at time $\mathrm{t}$;

Solution of Eq. (4) involves time integration to generate the response at discrete times at intervals $\Delta \mathrm{t}, 2 \Delta \mathrm{t}$, etc.

Initial conditions are required at time 0 , usually the building carrying gravity loads in the at-rest state.

In the presence of stiffness nonlinearity, the static displacements from gravity loads are computed from a solution of the equilibrium equations, as follows:

$\mathrm{F}(0)=\mathrm{P}^{\mathrm{G}} \ldots$

which is solved by an iterative process involving linearizations about successive approximations to the solution. For iteration $k$, based on current approximate displacements $\mathrm{U}^{k}(0)$ and corresponding stiffness forces $\mathrm{F}^{k}(0)$, the linearization statement is

$\mathrm{F}(0)=\mathrm{F}^{k}(0)+\mathrm{K}_{\mathrm{T}}^{k}(0) \Delta \mathrm{U}^{k} \ldots$

Substitution of Eq.(6) into Eq.(5) results in

$\mathrm{K}_{\mathrm{T}}{ }^{k}(0) \Delta \mathrm{U}^{k}=\mathrm{P}^{\mathrm{G}}-\mathrm{F}^{k}(0) \ldots$

from which the displacement increments) $\Delta \mathrm{U}^{k}$ are computed. The updated displacements are 


$$
\mathrm{U}^{k+1}(0)=\mathrm{U}^{k}(0)+\Delta \mathrm{U}^{k} \ldots
$$

and the corresponding stiffness forces $\mathrm{F}^{k+1}(0)$ are found from $\mathrm{F}^{k}(0)$ by following the subsequent actual nonlinear behavior through the increment.

Equations (7) and (8) define the iteration process, and iterations continue until convergence.

The numerical integration of the nonlinear equations (4) is performed employing the Newmark constant average acceleration method $(\beta=1 / 4$ and $\gamma=1 / 2)$ with Newton-Raphson type iterative technique to achieve equilibrium at the end of each time step.

Constant average acceleration, an implicit time integration scheme, uses the following time-stepping relations

$$
\begin{aligned}
& \ddot{\mathrm{U}}(\mathrm{t}+\Delta \mathrm{t})=\frac{4}{(\Delta \mathrm{t})^{2}}(\mathrm{U}(\mathrm{t}+\Delta \mathrm{t})-\mathrm{U}(\mathrm{t}))-\frac{4}{\Delta \mathrm{t}} \dot{\mathrm{U}}(\mathrm{t})-\ddot{\mathrm{U}}(\mathrm{t}) \cdots \\
& \dot{\mathrm{U}}(\mathrm{t}+\Delta \mathrm{t})=\dot{\mathrm{U}}(\mathrm{t})+\frac{1}{2}(\ddot{\mathrm{U}}(\mathrm{t})+\ddot{\mathrm{U}}(\mathrm{t}+\Delta \mathrm{t})) \Delta \mathrm{t} \cdots
\end{aligned}
$$

To define the $k^{\text {th }}$ iteration in the step from $\mathrm{t}$ to $\mathrm{t}+\Delta \mathrm{t}$, replace $\mathrm{U}(\mathrm{t}+\Delta \mathrm{t})$ in $\mathrm{Eq} .(9 \mathrm{a})$ by $\left(\mathrm{U}^{k}(\mathrm{t}+\Delta \mathrm{t})+\Delta \mathrm{U}^{k}\right)$, linearize the stiffness forces as

$\mathrm{F}(\mathrm{t}+\Delta \mathrm{t})=\mathrm{F}^{k}(\mathrm{t}+\Delta \mathrm{t})+\mathrm{K}_{\mathrm{T}}^{k}(\mathrm{t}+\Delta \mathrm{t}) \Delta \mathrm{U}^{k} \quad \cdots$

and substitute Eqs. (9) and (10) into Eq. (1) written at time $(\mathrm{t}+\Delta \mathrm{t})$ to obtain

$$
\begin{aligned}
& {\left[\frac{4}{(\Delta \mathrm{t})^{2}} \mathrm{M}+\frac{2}{\Delta \mathrm{t}} \mathrm{C}+\mathrm{K}_{\mathrm{T}}^{k}(\mathrm{t}+\Delta \mathrm{t})\right] \Delta \mathrm{U}^{\mathrm{k}}} \\
& =\mathrm{P}(\mathrm{t}+\Delta \mathrm{t})-\mathrm{F}^{k}(\mathrm{t}+\Delta \mathrm{t})-\left[\frac{4}{(\Delta \mathrm{t})^{2}} \mathrm{M}+\frac{2}{\Delta \mathrm{t}} \mathrm{C}\right] \mathrm{U}^{k}(\mathrm{t}+\Delta \mathrm{t}) \\
& +\left[\frac{4}{(\Delta \mathrm{t})^{2}} \mathrm{M}+\frac{2}{\Delta \mathrm{t}} \mathrm{C}\right] \mathrm{U}(\mathrm{t})+\left[\frac{4}{\Delta \mathrm{t}} \mathrm{M}+\mathrm{C}\right] \dot{\mathrm{U}}(\mathrm{t})+\mathrm{MU}(\mathrm{t})
\end{aligned}
$$

To carry out iteration $k$, Eq.(11) is solved for $\Delta \mathrm{U}^{k}$.

The new displacement approximation is found as

$$
\mathrm{U}^{k+1}(\mathrm{t}+\Delta \mathrm{t})=\mathrm{U}^{k}(\mathrm{t}+\Delta \mathrm{t})+\Delta \mathrm{U}^{k} \ldots
$$

and the updated stiffness forces $\mathrm{F}^{k+1}(\mathrm{t}+\Delta \mathrm{t})$ are computed from $\mathrm{F}^{k}(\mathrm{t}+\Delta \mathrm{t})$ by following the actual nonlinear behavior through the increment. After convergence, using the last approximation to $\mathrm{U}(\mathrm{t}+\Delta \mathrm{t})$, and the next time step commences.

Thus, calculated values of displacements are used as structural response model for EDPs.

\section{GROUND MOTION MODEL}

The recorded accelerograms may be used to represent earthquakes at a site. But there is a scarcity of strong motion records for Tbilisi region. Because of the lack of records, in this study, synthetic earthquake time histories are generated to reflect the region ( $100 \mathrm{~km}$ environment) site conditions.

The model of seismic ground motion used in this paper is a set of discrete nonstationary Gaussian process that differ from one another by dominant frequencies, duration and other parameters. The mentioned feature in a model of seismic effect allows to some extent take into account possible, physically realized diversity of spectral contents of various earthquakes and predict spectra of probable earthquake considering regional seismological data.

Each $j$ element of this set or the ground acceleration $\ddot{U}_{g}$ $\left(\mathrm{t}, \omega_{j}\right)$ is found as the product of a stationary Gaussian process $\mathrm{X}\left(\mathrm{t}, \omega_{j}\right)$ with zero mean and deterministic envelope function $\mathrm{A}\left(\mathrm{t}, \omega_{j}\right)$ in the domain $\omega_{\min }<=\omega_{j}<=\omega_{\max }$

$\ddot{\mathrm{U}}_{\mathrm{g}}\left(\mathrm{t}, \omega_{j}\right)=\mathrm{X}\left(\mathrm{t}, \omega_{j}\right) \mathrm{A}\left(\mathrm{t}, \omega_{j}\right) \ldots$

where $\omega_{j .}$ is dominant $j$-th process frequency, its boundary values $\omega_{\min }$ and $\omega_{\max }$ are assumed on the basis of empirical data.

The normalized envelope function is defined with fixed values $\omega_{j}$ by the following expression:

$\mathrm{A}\left(\mathrm{t}, \omega_{j}\right)=\varepsilon_{j}$ ete $^{-\varepsilon_{j} \mathrm{t}} \quad|\mathrm{A}|_{\max }=1 \ldots$

The random function is obtained in the form of

$\mathrm{X}\left(\mathrm{t}, \omega_{j}\right)=\sigma\left(\mathrm{t}, \omega_{j}\right) \mathrm{x}\left(\mathrm{t}, \omega_{j}\right) \ldots$

where $\sigma\left(\omega_{j}\right)$ is root mean square value of acceleration; $\mathbf{x}\left(\mathbf{t}, \omega_{j}\right)$ is normalized random function that is characterized by function of correlation as

$\mathrm{K}(\tau)=\mathrm{e}^{-\alpha_{j}|\tau|} \cos \omega_{j} \tau \cdots$

or

$\mathrm{K}(\tau)=\mathrm{e}^{-\alpha_{j}|\tau|}\left(\cos \omega_{j} \tau+\alpha_{j} / \omega_{j} \sin \omega_{j}|\tau|\right) \cdots$

Thus, the model expressed by Eq. (13) is completely determined with fixed values $\omega_{j}$ using three parameters: $\alpha$ is correlation coefficient, characterizing width of the spectrum; $\varepsilon$ determines the effective duration and process nonstationarity; $\sigma$ is random process intensity, that is defined by its dispersion.

The computation of the parameters of the predicted earthquakes was carried out at the eight seismogenic zones of Tbilisi region (100 km environment), that can reveal maximum seismic effect on the territory of the city (Rekvava 10ECEE 1994) [8].

Calculated parameters considering earthquake magnitude and hypocentral distance for the generation of synthetic accelerograms for Tbilisi territory are given in Table $\mathbf{1}$.

Table 1. Parameters of Design Accelerograms

\begin{tabular}{|c|c|c|c|c|}
\hline No Zone & $\begin{array}{c}\boldsymbol{\omega} \\
\left(\mathbf{s e c}^{-1}\right)\end{array}$ & $\begin{array}{c}\boldsymbol{\alpha} \\
\left(\mathbf{s e c}^{-1}\right)\end{array}$ & $\begin{array}{c}\boldsymbol{\varepsilon} \\
\left(\mathbf{s e c}^{-1}\right)\end{array}$ & $\begin{array}{c}\sigma \\
\mathbf{c m} / \mathbf{s e c}^{2}\end{array}$ \\
\hline \hline \multicolumn{5}{|c|}{$1^{\text {st }}$ group with M=6 } \\
\hline 12 & 34.88 & 17.44 & 0.56 & 91 \\
17 & 34.88 & 17.44 & 0.56 & 87 \\
16 & 33.05 & 16.52 & 0.53 & 77 \\
7 & 27.30 & 13.65 & 0.44 & 51 \\
\hline \multicolumn{5}{|c|}{$2^{\text {nd }}$ group with M=6.5 } \\
\hline 20 & 19.03 & 9.51 & 0.3 & 33 \\
\hline \multicolumn{5}{|c|}{$3^{\text {rd }}$ group with M=7 } \\
\hline 11 & 19.62 & 9.81 & 0.31 & 120 \\
4 & 17.44 & 8.72 & 0.28 & 74 \\
30 & 14.60 & 7.30 & 0.23 & 32 \\
\hline
\end{tabular}


Obtained results are discussed as an initial data for a ground motion IM or intensity model.

Thus, the variability due to several earthquake sources can be included in the seismic damage assessments of the structure.

\section{RELIABILITY ASSESSMENT}

After sample response histories of sufficient size are generated statistics are taken on the significant response quantities to determine their probabilistic parameters, which are in turn used for the reliability analysis of the building by means of Monte Carlo techniques by the computer code BUILDING-NL (Rekvava and Mdivani ITSAESE 2007) [4].

The building failure criterion is considered the moment when the roof relative deflection value exceeds its permissible one

$\left|\mathrm{U}_{\mathrm{r}} / \mathrm{H}\right|>\left[\mathrm{U}_{\mathrm{r}} / \mathrm{H}\right] \ldots$

where $U_{r}$ is the general roof horizontal deflection of the building; $\mathrm{H}$ is the building height; $\left[\mathrm{U}_{\mathrm{r}} / \mathrm{H}\right]=1 / 1200$ is allowable value of the given parameter for design (Poliakov SRCB 1983) [9].

For an alternative approach the reliability of structure $R_{s}$ can be also evaluated on the basis of statistical method by

$\mathrm{R}_{\mathrm{s}}=1-\mathrm{N}_{\mathrm{o}} / \mathrm{N}_{\mathrm{t}} \ldots$

where $\mathrm{N}_{\mathrm{o}}$ is number of failure event which is connected with the fulfillment of the condition $\left|U_{\mathrm{r}}\right|>\left[\mathrm{U}_{\mathrm{r}}\right]$ under seismic influence; $\mathrm{N}_{\mathrm{t}}$ is total number of roof deflections during seismic influence considered as a realization of random function.

Under the equal probability condition the following value of the reliability is defined

$\mathrm{R}_{\mathrm{s}}=\frac{1}{\mathrm{n}} \sum_{\mathrm{i}=1}^{\mathrm{n}} \mathrm{R}_{\mathrm{si}} \cdots$

where $\mathrm{n}$ is number of seismic influence.

The seismic resistance criterion of the panel building generally is written

$\mathrm{R}_{\mathrm{s}}>\mathrm{R}_{\mathrm{ul}} \ldots$

where $\mathrm{R}_{\mathrm{ul}}$ is the admissible reliability value and is adopted to be equal to $0.9-0.99$.

\section{SEISMIC ANALYSIS AND DISCUSSIONS}

The structure used in the analysis is 5-story and $15 \mathrm{~m}$ high panel building with wide 7.2-8.4 m spacing. Structural members are prefabricated from the lightweight concrete. The story weight is $2952 \mathrm{kN}$ for span of wall $7.2 \mathrm{~m}$ and 3240 $\mathrm{kN}$ for span of wall $8.4 \mathrm{~m}$. The building is situated in Tbilisi area at the class II soil type (medium, with soil shear wave velocity $300-800 \mathrm{~m} / \mathrm{s}$ ) according to soil classification (DC 01.01.09 2009)[10].

Fig. (3) shows a typical structural plan of the building.

The building is founded on the ground presented in appearance of a rectangular prism with sizes in plan $280 \times 170$ $\mathrm{m}$. The ground segment from a surface to basic bedrock consists of two layers $\left(\mathrm{H}_{1}=10 \mathrm{~m}\right.$ loam, $\mathrm{E}=58 \mathrm{MPa}$ and $\mathrm{H}_{2}=50 \mathrm{~m}$ clay, $\mathrm{E}=33 \mathrm{MPa}$ ) and 1426 elastic three dimensional finite

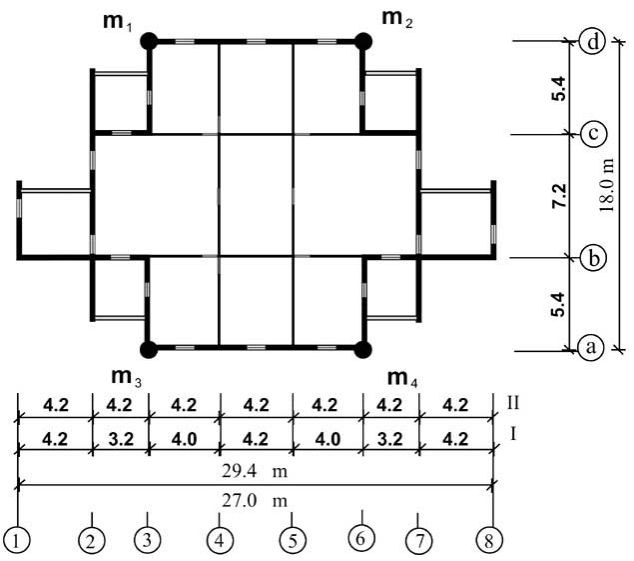

Fig. (3). Structural plan of the building.

elements with three translation degrees of freedom at each node. The 36 contact elements are arranged along the interaction surface between building and the soil. The maximum values of stiffness for contact elements in shear and compression are $\mathrm{K}_{\mathrm{x}}=25.6 \times 10^{4}$ and $\mathrm{K}_{\mathrm{z}}=36.5 \times 10^{4} \mathrm{kN} / \mathrm{m}$, respectively.

The initial (elastic) values of axial $\mathrm{K}_{\mathrm{a}}$ and shear stiffness $\mathrm{K}_{\mathrm{s}}$ determined on the basis of guidelines (BCR 2.08.01-85 1989) [11] for the given vertical and horizontal R/C key joints are: $\mathrm{K}_{\mathrm{a}}{ }^{\mathrm{V}}=432 * 10^{4} \mathrm{kN} / \mathrm{m}, \mathrm{K}_{\mathrm{s}}{ }^{\mathrm{V}}=32 * 10^{4} \quad \mathrm{kN} / \mathrm{m}$, $\mathrm{K}_{\mathrm{a}}{ }^{\mathrm{H}}=313^{*} 10^{4} \mathrm{kN} / \mathrm{m}, \mathrm{K}_{\mathrm{s}}{ }^{\mathrm{H}}=33^{*} 10^{4} \mathrm{kN} / \mathrm{m}$.

The design gravity loads adopted are: 1) the structure self-weight; 2) the design live load.

The building was subjected to the three components of the Tbilisi earthquake of April 25, 2002 with scaled PGA of $0.2 \mathrm{~g}$ and three-component synthetic accelerograms generated using the data of Table 1 for Tbilisi region of seismogenic zones $12,16,7$ and 11 were used.

Performance objective associated with an earthquake with $2 \%$ in 50 year probability is accounted for in the design.

The calculation was carried out on the basis of design model considering the nonlinear ductility of connections of structural elements, the contact surface between the building and ground and the initial conditions (strained state from static load) at mixed system of bearing walls spacing in the first version -4.2 and $7.2 \mathrm{~m}$, and in the second version -4.2 and $8.4 \mathrm{~m}$.

In Fig. (4) the first seven periods of natural vibration of the system are shown. It can be seen that increasing of the

$\mathrm{T}$, sec

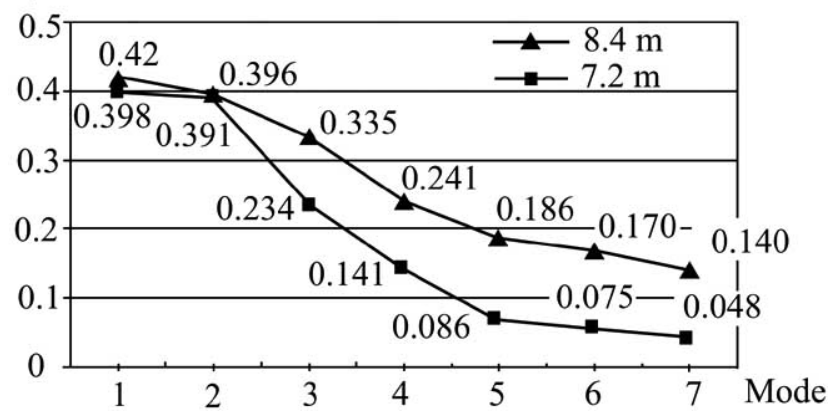

Fig. (4). Values of the periods. 
wall spacing up to $8.4 \mathrm{~m}$ conditions the increasing of initial fundamental period per $5 \%$, whereas the difference in the values of higher tones of period composes 30-60\%.

Fig. (5) shows the sample values of the maximum roof deflection for different dominant frequencies of seismic action.

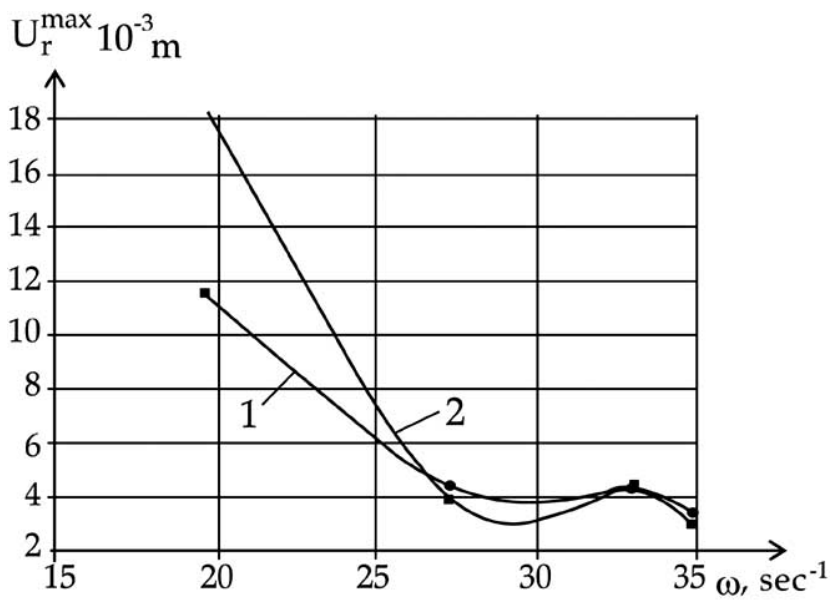

Fig. (5). Roof deflection 1- for $7.2 \mathrm{~m} ; 2$ - for $8.4 \mathrm{~m}$.

Figs. (6) and (7) summarize the maximum storey responses to five ground motions.

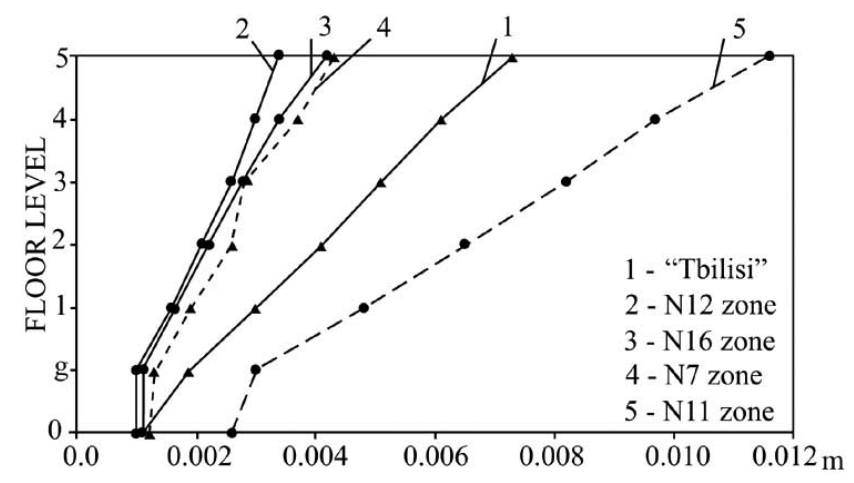

Fig. (6). Values of the story horizontal deflections for spacing 7.2 $\mathrm{m}$.

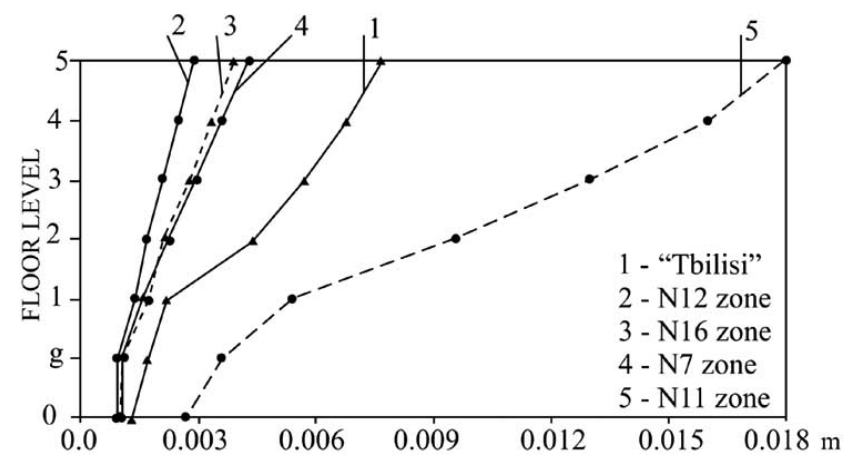

Fig. (7). Values of the story horizontal deflections for spacing 8.4 m.

The calculated extreme story drift distribution is illustrated in Fig. (8).
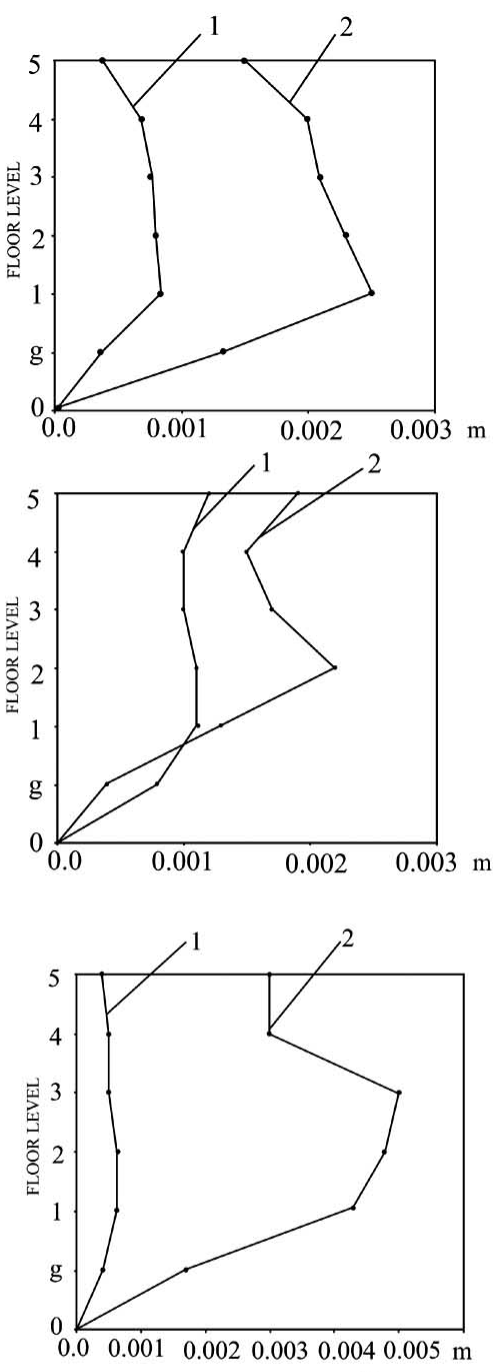

c

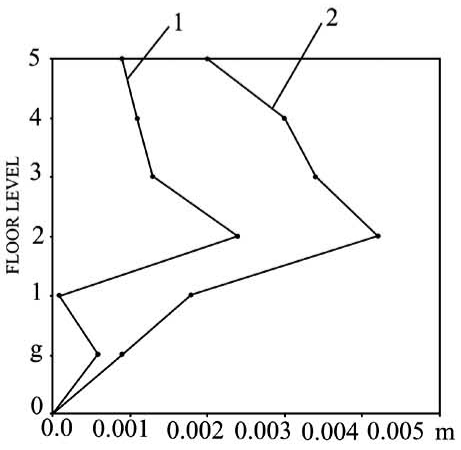

Fig. (8). Story drift of building for longitudinal (a,c) and transversal (b,d) directions: spacing 7.2 (a,b); spacing 8.4 (c,d). 1 -due to "Tbilisi" earthquake ; 2 - due to accelerogram from seismogenic zone 11

The analysis shows that during the elastic-plastic vibration of building with spacing of 7.2 and $8.4 \mathrm{~m}$ maximum roof horizontal relative deflection and stories drift ratios are less than $1 / 1200$ and $1 / 200$, respectively that indicates the great rigidity and the ability of a panel system with wide spacing under examination to resist to earthquakes of various spectral content. This is also confirmed by the displacement ductility demand $\left(\mu_{\mathrm{B}}\right)$ of the building that is ratio of the 
maximum displacement to the yield displacement and as numerical results showed its value equals 2 .

The value of slippage at elastic-plastic vibration on the interface of building-ground reaches its maximum at the spacing of $8.4 \mathrm{~m}$ at generated earthquake with the prevailing frequency $19.62 \mathrm{sec}-1$ (zone 11) and composes $0.0006 \mathrm{~m}$ that is 2.8 times greater then the effect of the 2002 Tbilisi earthquake.

The building maximum subsidence is $0.013 \mathrm{~m}$ that is less than the maximum allowable one for panel buildings.

In consideration of real and generated accelerograms there is no disturbance of the contact along the vertical axis of the building.

The increase of spacing up to $8.4 \mathrm{~m}$ does not cause damage of the panel slabs with exhausting of carrying capacity of the compressed cross-section.

The concentration of main tensile stress zones is observed in the joints of connection and exceeds the concrete design resistance in tension that conditions the local damages in these places.

The maximum compression stresses in the panels of external and internal walls at increasing of spacing up to $8.4 \mathrm{~m}$ are raised per $19-30 \%$, but they remain less then design compression resistance of the concrete of respective class. In the most strained panels of the first floor the cracks appear under action of accelerograms of zone 11, whereas the other earthquakes under consideration do not affect significantly the structure operation.

The deformation of key joints of structural elements has a complex character. The number of elastic-plastic cycles of deformation depending on the duration and spectral content of real earthquake and generated accelerograms reaches 1030 .

Cracks in the key joints and local damages are developed, but permanent displacements do not exceed the permissible ones in the horizontal $(0.03 \mathrm{~m})$ and vertical $(0.01 \mathrm{~m})$ directions. Here the normal (compression, tension) and shear forces are increased per 1.2-1.3 times in comparison with spacing of $7.2 \mathrm{~m}$, and compose respectively $56 \%$ and $41 \%$ of ultimate strength of indicated joints.

\section{CONCLUSIONS}

1. The method has been presented that is capable of accurate reproduction of the complete three-dimensional nonlinear behavior of the soil-interface-panel building system under strong ground motion in Tbilisi region and used to study the reliability of a residential 5-story panel building of new generation.

2. The bearing capacity of the panel building with the super-wide spacing $8.4 \mathrm{~m}$ is not exceeded. It resists the effect of an earthquake of high intensity and retains the ability of further deformation.
3. The code reduction coefficient $K_{1}=0.25$ (it is equal to $1 / q$, where $\mathrm{q}$ is the behavior factor used for design in Eurocode 8 ) considering the panel building capacity to develop the inelastic deformations, in this study composes 0.5 , that indicates the low degree of nonlinear deformability of the 5-story panel building.

4. The building reliability for both versions are equal to 0.95 that is greater than ultimate admissible one (0.9) for the dwelling houses that guarantees the structure safety from collapse and allows to recommend the expediency of experimental design and the construction of proposed building with super-wide wall spacing.

5. Degree of total damage of the building is less than 3 determined by MSK-64, that is connected with DM and does not cause the stopping of a building function and is not required a lot of financial expenses for repairing. Obtained results can be used for many decision-makers.

6. Further research needs tools for improved nonlinear analyses of the soil-interface-panel building system that includes a successful methodology for evaluation of monetary loss or DV as the last stage of PBEE of the examined type panel building for future seismic activity.

\section{REFERENCES}

[1] V. Caccese and H. G. Harris, "Seismic resistance of precast concrete shear walls-correlation of experimental and analytical results". Earthquake Engineering and Structural Dynamics, vol. 15, pp. 661-677, 1987.

[2] P. A. Rekvava, "Nonelastic ductility influence of nodes on seismic response of large panel buildings", in Proceedings of the 9-th European Conference on Earthquake Engineering, 1990, vol. 7-A, pp.118-126.

[3] S. Astarioglu, A. M . Memariz and A. Scanlon, "Modeling strategies for three dimensional analysis of precast panel buildings under seismic load", in Proceedings of the 12-th World Conference on Earthquake Engineering, 2000, Paper Reference 1356.

[4] P. A. Rekvava and K. I. Mdivani, "Investigation on seismic performances of precast R/C panel buildings", in Proceedings of the International Turkey Symposium on Advances in Earthquake and Structural Engineering, 2007, pp. 17-27.

[5] J. Moehle and G. G. Deierlein, "A framework methodology for performance-based earthquake engineering", in Proceedings of the 13-th World Conference on Earthquake Engineering, 2004, Paper Reference 679.

[6] P. A. Rekvava, "Method of plastic hinge joints in design panel building under seismic influence", in Proceedings of the 14-th World Conference on Earthquake Engineering, 2008, Paper Reference 14-014.

[7] F. E. Heuze and T. C. Barbour, "New models for rock joints and inerfaces“, Geotechnical Engineering Devision, vol. 108, pp.757776, 1982.

[8] P. A. Rekvava, "Use of the regional models of seismic effect in building design“, in Proceedings of the 10-th European Conference on Earthquake Engineering, 1994, vol.1, pp.253-256.

[9] S. V. Poliakov, Seismic Resistant Constructions of Buildings, Moscow: Building Publishing House, 1983.

[10] DC 01.01.09. Design code for earthquake engineering of Georgia, 2009.

[11] BCR 2.08.01-85. Guidelines of the panel dwelling-houses design, Moscow: Building Publishing House, 1989. 